\section{D) Check for updates}

Cite this: Dalton Trans., 2020, 49 9404

Received 8th May 2020,

Accepted 15th June 2020

DOI: $10.1039 / \mathrm{dOdt01674h}$

rsc.li/dalton

\title{
Substrate and product binding inside a stimuli- responsive coordination cage acting as a singlet oxygen photosensitizer $\uparrow$
}

\author{
Sonja Pullen, (iD \$ Susanne Löffler, \$ André Platzek, Julian J. Holstein (iD) and \\ Guido H. Clever (D)*
}

\begin{abstract}
An acridone-based, interpenetrated double cage $\left[3 \mathrm{BF}_{4} \mathrm{Pd}_{4} \mathrm{~L}_{8}\right]$ acts as a photosensitizer for generating singlet oxygen which adds to 1,3-cyclohexadiene in a [2+4] hetero-Diels-Alder reaction to form 2,3-dioxabicyclo[2.2.2]oct-5-ene. Photocatalytic activity was exclusively observed for the assembled cage, whereas the free organic ligand $\mathbf{L}$ decomposes upon irradiation. While cage $\left[\mathbf{B B F}_{4} \mathbf{P d}_{4} \mathbf{L}_{8}\right]$ does not accept any organic guests, NMR, MS and single crystal X-ray results reveal that both substrate and product are readily encapsulated in the central pocket of its chloride-activated form $\left[2 \mathbf{C l} \mathbf{a P d}_{\mathbf{4}} \mathrm{L}_{8}\right]$. The system combines multiple functions (photosensitization, allosteric activation and guest uptake) within a structurally complex, mechanically-bound self-assembly built up from a simple and readily accessible ligand.
\end{abstract}

\section{Introduction}

Supramolecular host compounds have garnered increasing attention with respect to applications in selective guest encapsulation $^{1-9}$ and catalysis. ${ }^{10-19}$ Coordination cages, assembled from metal cations and organic ligands with two or more donor groups, represent a versatile family of hosts with tunable size and properties. ${ }^{20,21}$ In equipping such cages with distinct functionality, the introduction of addressable features into the ligand backbones has been shown to be a fruitful strategy. The resulting structures can be responsive to external stimuli such as light, $\mathrm{pH}$ or addition of chemical inputs. ${ }^{22-27}$ For example, the implementation of photoswitches into the ligands allows to control light-induced processes such as complete structural rearrangement ${ }^{28}$ or guest uptake and release. ${ }^{29,30}$ Chromophore-based supramolecules can also be used to catalyse reactions. For example, Fujita and coworkers presented photoactive cages for alkane oxidation ${ }^{31}$ and the demethylation of cyclopropanes through guest-to-host electron transfer. $^{32}$

We have reported a series of interpenetrated double cages that form quantitatively from a mixture of square-planar Pd(II) cations and banana-shaped bis-monodentate pyridyl

Faculty of Chemistry and Chemical Biology, TU Dortmund University, Otto-Hahn Str. 6, 44227 Dortmund, Germany.E-mail: guido.clever@tu-dortmund.de

$\dagger$ Electronic supplementary information (ESI) available: Experimental details. CCDC 1952467 and 1952468. For ESI and crystallographic data in CIF or other electronic format see DOI: 10.1039/D0DT01674H

$\$$ These authors contributed equally to this work. ligands with dibenzo-suberone, phenothiazine or similar backbones. ${ }^{33-37}$ The mechanically-bound structures have three pockets, initially all filled with $\mathrm{BF}_{4}{ }^{-}$counter anions, of which the outer two can be exchanged by halide anions following an allosteric mechanism with strong positive cooperativity. ${ }^{33,38}$

A particularly interesting guest inclusion behaviour was observed for the derivative $\left[\mathbf{3} \mathbf{B} \mathbf{F}_{\mathbf{4}} @ \mathbf{P d}_{\mathbf{4}} \mathbf{L}_{\mathbf{8}}\right]$, assembled from acridone-based ligands (Fig. 1). Addition of chloride anions

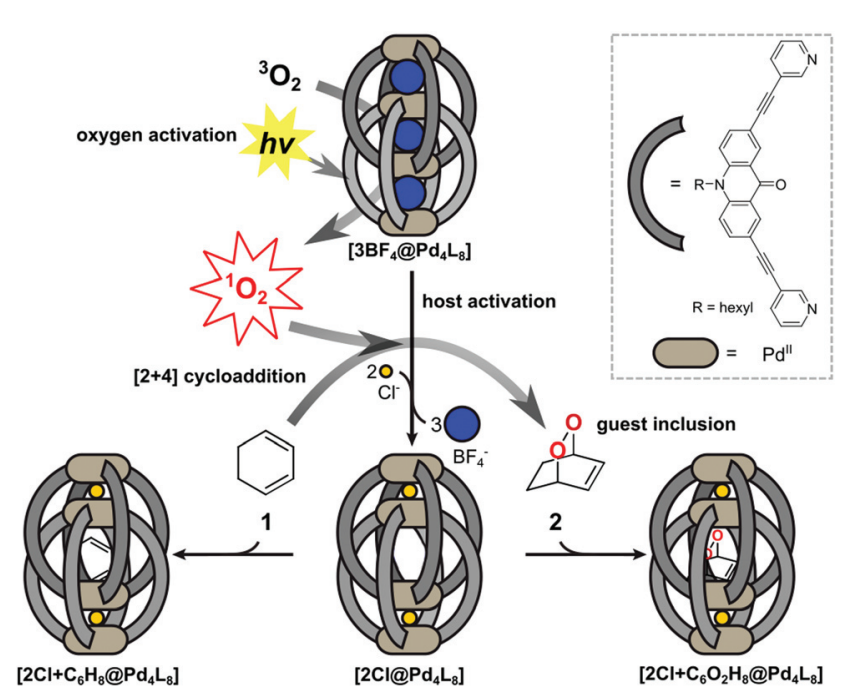

Fig. 1 Catalytic function and guest inclusion behaviour of the acridone-based double cages $\left[3 \mathrm{BF}_{4}\left(\mathrm{CPd}_{4} \mathrm{~L}_{8}\right]\right.$ and $\left[2 \mathrm{Cl}\left(\mathrm{aPd}_{4} \mathrm{~L}_{8}\right]\right.$ : both cages are able to generate singlet oxygen, reacting in a [2+4] cycloaddition reaction with 1,3 -cyclohexadiene. Only [ $2 \mathrm{Cl}^{\mathrm{aPd}} \mathrm{Pd}_{4} \mathrm{~L}_{8}$ ] is able to encapsulate both substrate 1 and product 2 . 
to this species leads to the quantitative conversion into [2Cl@Pd $\left.\mathbf{P d}_{\mathbf{4}} \mathbf{L}_{\mathbf{8}}\right]$ with an enlarged inner pocket that allows the encapsulation of neutral guest molecules such as benzene, cyclohexane or norbornadiene. ${ }^{39}$ This phenomenon could be explained by the compression of the catenated cage structure along the $\mathrm{Pd}_{4}$-axis due to the small chloride anions replacing larger $\mathrm{BF}_{4}{ }^{-}$species, resulting in the expansion of the central pocket, hence activating the host to accept a variety of guests.

Six-membered rings, including bridged derivatives (i.e. norbornane- and bicyclooctane-type compounds), were found to be favourably accepted for encapsulation as compared to smaller or larger molecules. ${ }^{40}$ By comparing the results of systematic guest affinity experiments with high-level electron correlation calculations, London dispersion interactions were recognized as the main contributor to the driving force for neutral guest inclusion inside the central pocket of the charged host. ${ }^{41}$
Encouraged by these observations, we moved on to test the ability of $\left[2 \mathbf{C l} @ \mathbf{P d}_{4} \mathbf{L}_{8}\right]$ to take a role in catalytic reactions. Owing to the known dimensions of the central cavity and its preference for bicyclic organic compounds, we envisioned to conduct electrocyclic reactions inside the confined cavity. As a first example, we present the encapsulation of 1,3-cyclohexadiene 1, which is a common substrate for Diels-Alder reactions. ${ }^{42}$

\section{Results and discussion}

\section{Synthesis of host-guest complexes}

$\left[3 \mathbf{B F}_{4} @ \mathbf{P d}_{\mathbf{4}} \mathbf{L}_{\mathbf{8}}\right]$ and $\left[\mathbf{2} \mathbf{C l} @ \mathbf{P d}_{\mathbf{4}} \mathbf{L}_{\mathbf{8}}\right]$ were prepared according to our previously described procedure. ${ }^{39}$ The encapsulation of 1

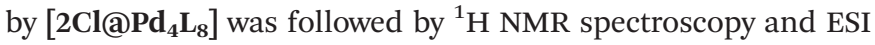
mass spectrometry (Fig. 2a and c). After addition of 30 equivalents of $\mathbf{1}$ to an acetonitrile solution of the host and incubating
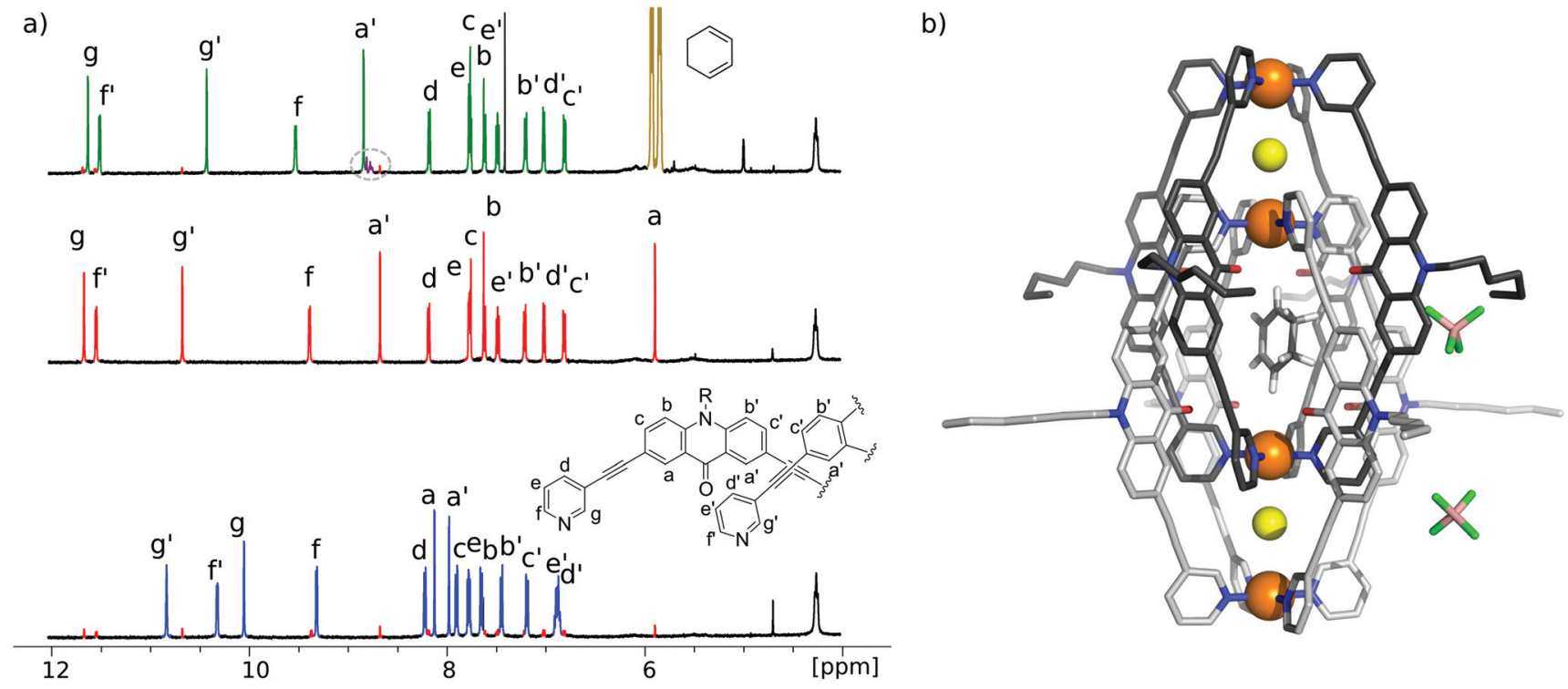

c)

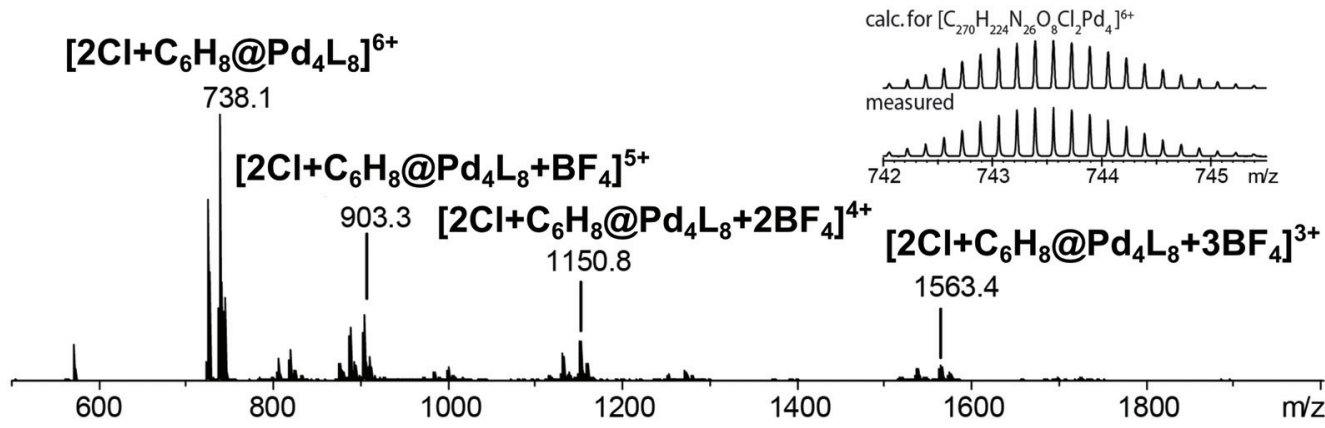

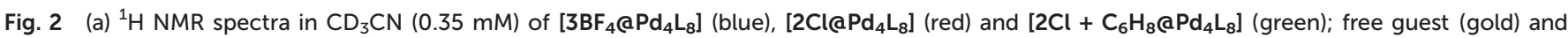
bound guest (purple; highlighted by a grey circle). (b) X-ray crystal structure of $\left[2 \mathrm{Cl}+\mathrm{C}_{6} \mathrm{H}_{8} @ \mathrm{Pd}_{4} \mathrm{~L}_{8}\right]$ (colour scheme: $\mathrm{C}$ : light/dark grey; $\mathrm{N}$ : blue; $\mathrm{O}$ : red; $\mathrm{Cl}$ : yellow; F: green; $\mathrm{B}$ : salmon; Pd: orange, and $\mathrm{H}$ : white). The neutral guest molecule 1 was modelled in the central pockets of the cavity based on NMR and ESI-MS results and in agreement with the crystallographic data. It is depicted to adopt one of four symmetry-equivalent positions. For clarity, the hydrogen atoms of the coordination cage, co-crystallized solvent molecules and some of the counter anions were removed. (c) ESI-MS spectrum of the host-guest complex $\left[2 \mathrm{Cl}+\mathrm{C}_{6} \mathrm{H}_{8} @ \mathrm{Pd}_{4} \mathrm{~L}_{8}\right]$. 
the sample at room temperature for $24 \mathrm{~h}$, a new set of signals were observed in the ${ }^{1} \mathrm{H}$ NMR spectrum (Fig. 2a). A binding constant of $2.15( \pm 0.04) \times 10^{3} \mathrm{~L} \mathrm{~mol}^{-1}$ for 1 was determined via ${ }^{1} \mathrm{H}-\mathrm{NMR}$ signal integration of the equilibrated mixture of free host/guest and host-guest complex in slow exchange at $298 \mathrm{~K}$ (for details see ESI $\dagger$ ). For the latter one, protons $\mathrm{H}_{\mathrm{g}^{\prime}}$ and $\mathrm{H}_{\mathrm{a}^{\prime}}$, which point inside the central pocket of the interpenetrated coordination cage, were found to be shifted significantly; $\mathrm{H}_{\mathrm{g}^{\prime}}$ shifted upfield by $\Delta \delta=0.25 \mathrm{ppm}$ and $\mathrm{H}_{\mathrm{a}^{\prime}}$ shifted downfield by $\Delta \delta=0.16 \mathrm{ppm}$. Similar shifts were observed previously for the inclusion of other neutral guests. ${ }^{39,42}$ Based on these chemical shifts, we conclude that encapsulation of $\mathbf{1}$ takes place inside the central pocket of the chloride-activated coordination cage. In addition, high-resolution ESI mass spectrometry showed a series of species $\left[\mathbf{2} \mathbf{C l}+\mathbf{C}_{\mathbf{6}} \mathbf{H}_{\mathbf{8}} @ \mathbf{P d}_{\mathbf{4}} \mathbf{L}_{\mathbf{8}}+\mathbf{n} \mathbf{B} \mathbf{F}_{\mathbf{4}}\right]^{(\mathbf{6}-\boldsymbol{n})+}(n=0-3)$ with a variable number of tetrafluoroborate counter anions, confirming the formation of the host-guest complex (Fig. 2c). In contrast, the addition of 30 eq. 1 to the precursor cage [3 $\left.3 \mathbf{B F}_{4} @ \mathbf{P d}_{4} \mathbf{L}_{8}\right]$ did not result in any change of the cage's ${ }^{1} \mathrm{H}$-NMR signals (ESI, Fig. S1 $\dagger$ ). This was expected as the neutral guest uptake only occurs in the presence of halide anions that trigger the enlargement of the central pocket. ${ }^{39}$

\section{Single crystal X-ray structure}

Single crystals of $\left[\mathbf{2} \mathbf{C l}+\mathbf{C}_{\mathbf{6}} \mathbf{H}_{\mathbf{8}} @ \mathbf{P d}_{\mathbf{4}} \mathbf{L}_{\mathbf{8}}\right]$ were obtained via slow vapor diffusion of diethyl ether into an acetonitrile solution of the host-guest complex. X-ray data measured at a synchrotron radiation source reveal that the supramolecular structure consists of two monomeric cage units which interlace into the $\left[\mathbf{P d}_{\mathbf{4}} \mathbf{L}_{\mathbf{8}}\right]$ double cage architecture (Fig. 2b). The structure crystallized in space group $P 4 / n c c$ with one fourth of the double cage in the asymmetric unit. Similar to results obtained in previous guest inclusion studies, the structure features three pockets, the outer two occupied by a chloride anion and the inner void occupied by the neutral guest molecule $\mathbf{1}\left(\mathrm{C}_{6} \mathrm{H}_{8}\right)$. The crystallographic analysis was complicated as the encapsulated guest molecule $\mathbf{1}$ is disordered over a special position (4-fold axis). Therefore, it is able to reside in four different, symmetry-equivalent orientations in the cavity, each of which shows an occupancy of $25 \%$. Hence, the crystallographic data alone did not allow us to unequivocally interpret the exact coconformation of host and guest in the complex. We solved this problem by modelling one cyclohexadiene guest molecule inside the cavity (in accordance with NMR spectroscopic and mass spectrometric data) and evaluated the crystallographic model using an omit map (see ESI, Fig. S21 $\dagger$ ). As a result, the guest in $\left[\mathbf{2} \mathbf{C l}+\mathbf{C}_{\mathbf{6}} \mathbf{H}_{\mathbf{8}} @ \mathbf{P d}_{\mathbf{4}} \mathbf{L}_{\mathbf{8}}\right]$ is slightly tilted off the vertical axis between the palladium cations flanking the inner void. The distances between the palladium cations for the outer pockets are $6.4 \AA$ and for the inner cavity $10.6 \AA$. Modelling and refinement details can be found in the ESI. $\dagger$

\section{Photocatalysis}

1,3-Cyclohexadiene $\mathbf{1}$ is known to undergo a [4+2] cycloaddition with atmospheric oxygen in the presence of a photosensitizer such as Rose Bengal $(\mathrm{RB})^{43}$ or tetraphenylpor- phyrin (TPP $)^{44}$ under irradiation. The main product in this reaction is endoperoxide 2 with yields of $71 \%$ and $80 \%$, respectively. Photosensitization produces singlet oxygen by triplet energy transfer from the dye molecules. Besides its biological relevance, for example in the oxidation of cholesterol, ${ }^{45}$ singlet oxygen is frequently used in synthetic organic photochemistry. ${ }^{46,47}$ A major problem with the typically employed dyes RB, TPP or methylene blue is their lack of longterm stability. ${ }^{48}$

As acridone derivatives were reported before to serve as photosensitizers for singlet oxygen generation, ${ }^{48}$ we first tested ligand $\mathbf{L}$ for its ability to catalyse the photoreaction. However, ligand $\mathbf{L}$ turned out to be too light sensitive and even needs to be stored in the dark to prevent decomposition. Pleasingly, this lack of stability was completely abolished after cage assembly: both $\left[3 \mathbf{B F}_{\mathbf{4}} @ \mathbf{P d}_{\mathbf{4}} \mathbf{L}_{\mathbf{8}}\right]$ and $\left[\mathbf{2} \mathbf{C l} @ \mathbf{P d}_{\mathbf{4}} \mathbf{L}_{\mathbf{8}}\right]$ did not show significant degradation after being exposed to light, even after several weeks. Encouraged by this observation, we anticipated that the acridone-based cages will be sufficiently stable as triplet photosensitizers.

Free acridone ligand $\mathbf{L}$ shows two absorption maxima at 262 and $357 \mathrm{~nm}$ with a shoulder at $319 \mathrm{~nm}$. These bands are slightly blue shifted for the cages and the absorption of the shoulder is increased. $\left[\mathbf{2} \mathbf{C l} @ \mathbf{P d}_{\mathbf{4}} \mathbf{L}_{\mathbf{8}}\right]$ has three absorption maxima at 265, 231 and $360 \mathrm{~nm}$ and $\left[\mathbf{3 B F}_{\mathbf{4}} @ \mathbf{P d}_{\mathbf{4}} \mathbf{L}_{\mathbf{8}}\right.$ ] has three absorption maxima at 265, 231 and $362 \mathrm{~nm}$ (ESI, Fig. S21†).

For testing photochemical oxygen activation, [2Cl@ $\mathbf{P d}_{\mathbf{4}} \mathbf{L}_{\mathbf{8}}$ ] was freshly prepared in $\mathrm{CD}_{3} \mathrm{CN}$ and 30 eq. of guest 1 was added. After an incubation time of $24 \mathrm{~h},{ }^{1} \mathrm{H}$ NMR spectroscopy confirmed the formation of the host-guest complex $[2 \mathbf{C l}+$ $\left.\mathbf{C}_{6} \mathbf{H}_{8} @ \mathbf{P d}_{4} \mathbf{L}_{8}\right]$ in addition to a small amount of free host [2Cl@Pd $\mathbf{P}_{\mathbf{8}}$ ] (Fig. 3a and ESI, Fig. S4 $\dagger$ ). The sample was placed in a sealed screw cap vial $\left(0.35 \mathrm{mM}\right.$ [2Cl@Pd $\mathbf{P}_{\mathbf{4}}$ ], sample volume $1 \mathrm{~mL}$ ) and irradiated at room temperature in a photoreactor $^{49}$ for 40 minutes with a $365 \mathrm{~nm}$ LED source $(3.4 \mathrm{~W})$. Subsequently, the ${ }^{1} \mathrm{H}$ NMR signals of the cage protons $\mathrm{H}_{\mathrm{g}}, \mathrm{H}_{\mathrm{g}^{\prime}}$ and $\mathrm{H}_{\mathrm{a}^{\prime}}$ that are pointing inside the cavities shifted significantly, indicating a reaction of the encapsulated species (Fig. 3a). Furthermore, a new set of signals appeared at chemical shifts of $\delta=6.63,4.60,2.22$ and 1.43 ppm (Fig. 3b), matching with the reported literature values of endoperoxide 2 in $\mathrm{CD}_{3} \mathrm{CN}$ solution. ${ }^{50}$ Full conversion of 1 was observed, and endoperoxide product 2 had been formed as the main species. Hydroperoxide 3 was observed as a side product, which is the product of an ene reaction to singlet oxygen (light blue signals in Fig. 3). ${ }^{4}$

Interestingly, proton signals for inward pointing $\mathrm{H}_{\mathrm{g}}, \mathrm{H}_{\mathrm{g}^{\prime}}$ and $\mathrm{H}_{\mathrm{a}^{\prime}}$ of the double cage were found to split into three sets, one assigned to $\left[\mathbf{2 C l}+\mathbf{2} @ \mathbf{P d}_{\mathbf{4}} \mathbf{L}_{\mathbf{8}}\right]$, marked orange in Fig. 3a, and two further sets highlighted in turquoise. We assume that one of the latter signal sets stems from host including side product 3. The third group of signals may result from encapsulation of yet another product isomer or caused by 3 adopting a different, sterically locked position inside the host pocket. With the help of a DOSY experiment (ESI, Fig. S11 $\dagger$ ), we could 
a)
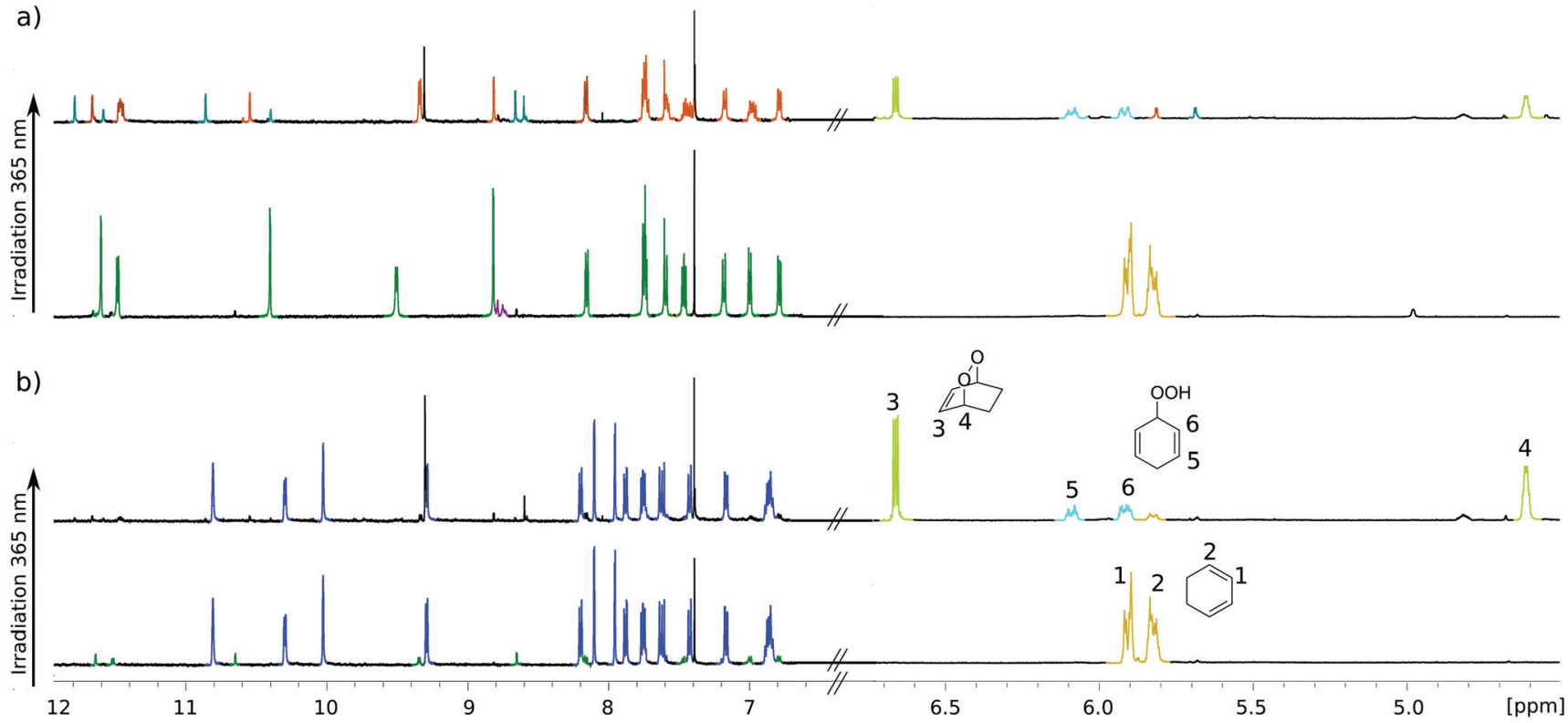

Fig. 3 (a) ${ }^{1} \mathrm{H}$ NMR spectra of $\left[2 \mathrm{ClOPd}_{4} \mathrm{~L}_{8}\right](0.35 \mathrm{mM})$ in the presence of 1,3 -cyclohexadiene 1 (30 eq.) before (green) and after (orange and turquoise) irradiation with a $365 \mathrm{~nm}$ LED in the presence of air for 40 minutes. The transformation of 1 (gold) into products 2 (lime) and 3 (light blue) as observed in the same NMR spectrum (depicted in an expanded format in the right half). (b) ${ }^{1} \mathrm{H}$ NMR spectra of [3BF $\left.{ }_{4} @ \mathrm{Pd}_{4} \mathrm{~L}_{8}\right](0.35 \mathrm{mM})$ in the presence of 1 (30 eq.) (blue) before and after irradiation with 365 nm LED for 40 minutes. Right: conversion of 1 into 2 and 3 by [3BF ${ }_{4} @ \mathrm{Pd}_{4} \mathrm{~L}_{8}$ ].

Table 1 [2+4] Hetero-Diels-Alder reaction of singlet $\mathrm{O}_{2}$ and 1 to form 2

\begin{tabular}{lllll}
\hline & & & \\
& 1 & & 2 & 3 \\
\hline
\end{tabular}

${ }^{a} 0.35 \mathrm{mM}\left(\hat{=} 2.8 \mathrm{mM}\right.$ ligand) solution of the cage in $\mathrm{CD}_{3} \mathrm{CN}, 30$ eq. of 1 under air. Irradiation with $365 \mathrm{~nm}$ LED. Yield determined by ${ }^{1} \mathrm{H}$ NMR spectroscopy. Average of three samples. ${ }^{b} 0.7 \mathrm{mM}$ in $\mathrm{CD}_{3} \mathrm{CN} .{ }^{c} 2.8 \mathrm{mM}$ in $\mathrm{CD}_{3} \mathrm{CN}$.

confirm that all signal sets belong to species with the size of the double cage.

In order to confirm that species [2Cl@Pd $\left.\mathbf{P d}_{\mathbf{4}} \mathbf{L}_{\mathbf{8}}\right]$ served as a photocatalyst, we performed a series of control experiments, summarized in Table 1. First, addition of $\mathbf{1}$ to $\left[\mathbf{2 C l} @ \mathbf{P d}_{\mathbf{4}} \mathbf{L}_{\mathbf{8}}\right.$ ] under argon shows no formation of peroxides 2 or 3 , which clearly confirms that a light induced [4+2] cycloaddition is taking place only in the presence of molecular oxygen (ESI,
Fig. S12 $\dagger$ ). When only 1 in $\mathrm{CD}_{3} \mathrm{CN}$ was irradiated for 40 minutes, the solution turned brown with the formation of a sluggish precipitate and the ${ }^{1} \mathrm{H}$ NMR spectrum shows neither substrate nor product signals (ESI, Fig. S13†). Likewise, a mixture of free acridone ligand $\mathbf{L}\left(2.8 \mathrm{mM}\right.$ in $\left.\mathrm{CD}_{3} \mathrm{CN}\right)$ and $\mathbf{1}$ resulted in decomposition of both $\mathbf{L}$ and $\mathbf{1}$ after 40 minutes of irradiation as indicated by the formation of a brown precipitate and disappearance of ${ }^{1} \mathrm{H}$ NMR signals corresponding to the ligand and substrate (ESI, Fig. S14 $\dagger$ ). In order to better mimic the electronic situation of a single acridone ligand as part of the cage, we prepared the complex $\left[\mathbf{L}(\mathbf{P d} \text {-terpy) })_{2}\right]$ (terpy $=2,2^{\prime}: 6^{\prime}, 2^{\prime \prime}$-terpyridine), in which two terpy-capped palladium cations are coordinated to both pyridine nitrogen donors of the ligand (see the $\mathrm{ESI}_{\dagger} \dagger$ for synthesis conditions and characterization). Intriguingly, this species did not perform as a catalyst either, as demonstrated by ${ }^{1} \mathrm{H}-\mathrm{NMR}$ analysis (ESI, Fig. S15 $\dagger$ ). Altogether, these experiments point to an intrinsic photocatalytic activity of the coordination cage [2Cl@Pd $\left.\mathbf{P d}_{\mathbf{4}} \mathbf{L}_{\mathbf{8}}\right]$. Previously, we have reported a $\left[\mathbf{P d}_{2} \mathbf{L}_{4}\right]$ cage with the same acridone backbone, but with isoquinoline instead of pyridine donor groups, which did not lead to cage dimerization. ${ }^{51}$ Under the same reaction conditions, this cage performed similarly to $\left[2 \mathbf{C l} @ \mathbf{P d}_{4} \mathbf{L}_{8}\right.$ ] (Table 1 and ESI, Fig. S19†), showing that cage interlocking is not necessary for photocatalytic activity.

Next, we addressed the question whether the reaction takes place inside the central pocket of $\left[2 \mathbf{C l} @ \mathbf{P d}_{\mathbf{4}} \mathbf{L}_{\mathbf{8}}\right]$. As stated above, the neutral substrate is taken up by the cage as a guest only in the presence of chloride anions. To probe whether substrate encapsulation was a prerequisite for a successful heteroDiels-Alder reaction, 30 equivalents of $\mathbf{1}$ were added to a solu- 


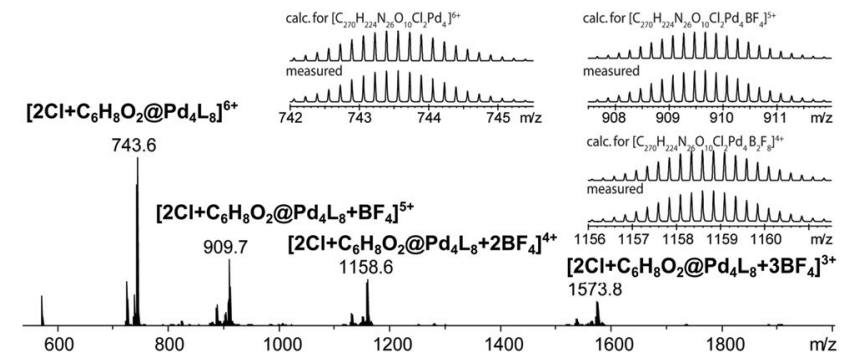

Fig. 4 ESI-MS spectrum of the host-guest complex $[2 \mathrm{Cl}+$ $\mathrm{C}_{6} \mathrm{H}_{8} \mathrm{O}_{2} @ \mathrm{CPd}_{4} \mathrm{~L}_{8}$ ] obtained by the slow photosensitization of a cage-substrate mixture in the presence of air after 94 days.

tion of $\left[\mathbf{3 B F}_{\mathbf{4}} @ \mathbf{P d}_{\mathbf{4}} \mathbf{L}_{\mathbf{8}}\right]$ and the mixture was irradiated for 40 minutes in the presence of atmospheric oxygen. Interestingly, about $88 \%$ of 1 was converted into 2 as the major product (Fig. 3b). Further irradiation for 40 minutes resulted in the complete conversion of 1 (ESI, Fig. S1 $\dagger$ ). Importantly, cage $\left[\mathbf{3} \mathbf{B F}_{\mathbf{4}} @ \mathbf{P d}_{\mathbf{4}} \mathbf{L}_{\mathbf{8}}\right]$ itself is not affected by irradiation as no change in its ${ }^{1} \mathrm{H}-\mathrm{NMR}$ spectrum was observed. Since the tetrafluoroborate-containing coordination cage $\left[3 \mathbf{B F}_{\mathbf{4}} @ \mathbf{P d}_{\mathbf{4}} \mathbf{L}_{\mathbf{8}}\right]$ does not have any vacant pockets, it can be concluded that the hetero-Diels-Alder reaction is not dependent on encapsulation of $\mathbf{1}$.

In order to improve the selectivity of the reaction towards single product 2 , we reduced the light intensity of the LED to $50 \%$ (ESI, Fig. S16 $\dagger$ ) or $20 \%$ (ESI, Fig. S17†) in order to slow down the reaction and yield only product 2 , without success. Then, we performed the reaction at $5{ }^{\circ} \mathrm{C}$, which was reported to be the optimal temperature with Rose Bengal as the photosensitizer. ${ }^{43}$ Also, under this condition, similar amounts of side product 3 were observed in the ${ }^{1} \mathrm{H}$ NMR spectrum (ESI, Fig. S18†).
Finally, we were able to maximize the formation of product 2 by leaving the sample in ambient daylight for 94 days. Here, the formation of compound 2 and its host-guest complex $\left[\mathbf{2 C l}+\mathbf{2} @ \mathbf{P d}_{4} \mathbf{L}_{8}\right]$ were clearly observed to be the only products. The ${ }^{1} \mathrm{H}$-NMR-signals of the host-guest complex correspond to the chemical shifts marked in orange in Fig. 3a (compare ESI, Fig. S20†). The hypothesis that the signal splitting described above is a result of different encapsulated products was thus confirmed. High resolution ESI mass spectrometry showed signals corresponding to $[2 \mathrm{Cl}+$ $\left.\mathbf{C}_{6} \mathbf{H}_{8} \mathbf{O}_{2} @ \mathbf{P d}_{4} \mathbf{L}_{8}+n \mathbf{B F}_{4}\right]^{(\mathbf{6}-n)+}(n=0-3)$ (Fig. 4), thus confirming the encapsulation of a species with a chemical formula of $\mathrm{C}_{6} \mathrm{H}_{8} \mathrm{O}_{2}$.

To our delight, we were able to obtain single crystals of $\left[2 \mathbf{C l}+\mathbf{C}_{6} \mathbf{H}_{8} \mathbf{O}_{2} @ \mathbf{P d}_{4} \mathbf{L}_{8}\right]$ via slow vapor diffusion of diethyl ether into an acetonitrile solution of the host-guest complex. The crystal structure is similar to the structure of $\left[\mathbf{2 C l}+\mathbf{C}_{6} \mathbf{H}_{\mathbf{8}} @ \mathbf{P d}_{\mathbf{4}} \mathbf{L}_{\mathbf{8}}\right]$ and also crystallized in the space group $P 4 / n c c$ with one fourth of the double cage architecture in the asymmetric unit. Similar to the $\left[\mathbf{2 C l}+\mathbf{C}_{\mathbf{6}} \mathbf{H}_{\mathbf{8}} @ \mathbf{P d}_{\mathbf{4}} \mathbf{L}_{\mathbf{8}}\right]$ structure, the guest is positioned on the four-fold axis and was modelled in the inner cavity in accordance with the NMR spectroscopic and mass spectrometric data. The omit map (Fig. 5 and Fig. S22 $\dagger$ ) confirms the consistency of this position with the crystallographic data. The palladium-palladium distances in the $\left[2 \mathbf{C l}+\mathbf{C}_{6} \mathbf{H}_{8} \mathbf{O}_{2} @ \mathbf{P d}_{4} \mathbf{L}_{8}\right]$ complex are $6.4 \AA$ for the outer pockets and $10.7 \AA$ for the inner pockets. Guest 2 is slightly tilted off the vertical axis between the palladium cations in the central cavity of the interpenetrated coordination cage with the shortest palladium-guest distance measuring 3.0 A. Close intermolecular contacts between the acridone ligands of the cage and neutral guest 2 were measured to range from 2.3 to $3.3 \AA$. The shortest intermolecular $\mathrm{CH} \cdots \mathrm{O}$ contact is $2.6 \AA$.
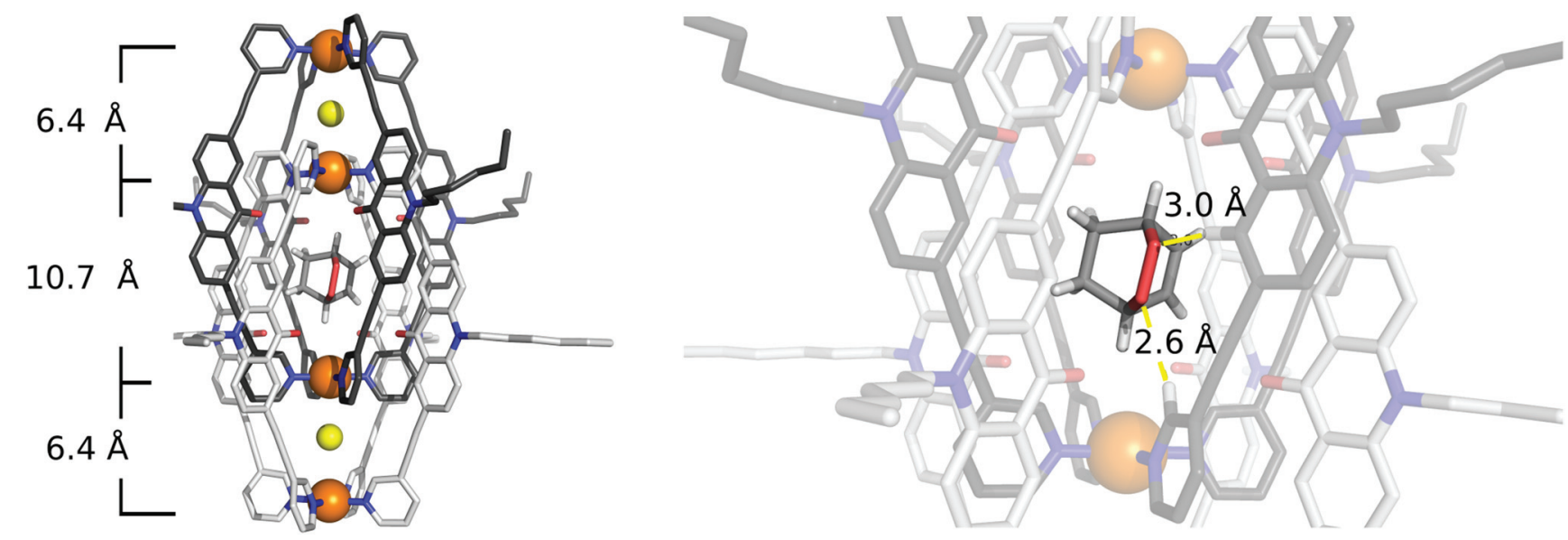

Fig. 5 X-ray crystal structure of $\left[2 \mathrm{Cl}+\mathrm{C}_{6} \mathrm{H}_{8} \mathrm{O}_{2} \mathrm{aPd}_{4} \mathrm{~L}_{8}\right]$ (colour scheme: C: light/dark gray; $\mathrm{N}$ : blue; O: red; $\mathrm{Cl}$ : yellow; $\mathrm{F}$ : green; $\mathrm{B}$ : salmon; $\mathrm{Pd}$ : orange, and $\mathrm{H}$ : white). Neutral guest molecule 2 in the central pocket of the cavity was modelled based on the NMR and ESI-MS results consistent with the crystallographic data. It is depicted to adopt one of four symmetry-equivalent positions. For clarity, hydrogen atoms of the coordination cage, co-crystallized solvent molecules and counter anions outside the cage structure were removed. 


\section{Conclusions}

We demonstrated the ability of interpenetrated coordination cages [2Cl@Pd $\left.\mathbf{P}_{\mathbf{4}} \mathbf{L}_{8}\right]$ and $\left[\mathbf{3 B F}_{\mathbf{4}} @ \mathbf{P d}_{\mathbf{4}} \mathbf{L}_{\mathbf{8}}\right]$ to convert 1,3-cyclohexadiene $\mathbf{1}$ in the presence of atmospheric oxygen and light into the peroxides 2,3-dioxabicyclo[2.2.2] oct-5-ene 2 and 3-hydroperoxycyclohexa-1,4-diene 3. The metal-mediated supramolecular assembly stabilizes the acridone ligand toward photodegradation and thus enables its photochemical activity. As shown by ${ }^{1} \mathrm{H}$ NMR spectroscopy, high-resolution mass spectrometry and X-ray structure analysis, [2Cl@ $\mathbf{P d} \mathbf{d}_{\mathbf{4}} \mathbf{L}_{8}$ ] readily encapsulates both substrate and product of the examined reaction. Photocatalytic activity, however, is not restricted to the host-guest complex. Also, the unbound substrate in the presence of either one of the coordination cages is converted to the peroxide. In future studies, we will extend the substrate scope for this reaction and examine the system's capability to catalyse further electrocyclic reactions.

\section{Conflicts of interest}

There are no conflicts to declare.

\section{Acknowledgements}

This work was supported by the Research Training group 'Confinement-controlled Chemistry', funded by the Deutsche Forschungsgemeinschaft (DFG) under Grant GRK2376/ 331085229. Further support by the DFG through grants CL 489/2-2 and SPP1807 is acknowledged. S. P. and G. H. C. thank the European Research Council for supporting the project with a Marie-Sklodowska Curie Individual Fellowship (MOCCA Project No. 798103 ). Single crystal X-ray diffraction data of $\left[\mathbf{2 C l}+\mathbf{C}_{6} \mathbf{H}_{\mathbf{8}} @ \mathbf{P d}_{\mathbf{4}} \mathbf{L}_{\mathbf{8}}\right]$ was collected at Petra III, DESY (a member of the Helmholtz Association, HGF), Hamburg, Germany. Anja Burkhardt is thanked for assistance in using macromolecular beamline P11 and travel grants from DESY are gratefully acknowledged (I-20160736).

\section{Notes and references}

1 R. Custelcean, Chem. Soc. Rev., 2014, 43, 1813-1824.

2 M. M. J. Smulders and J. R. Nitschke, Chem. Sci., 2012, 3, 785-788.

3 S. Pullen and G. H. Clever, Acc. Chem. Res., 2018, 51, 30523064.

4 T. R. Cook, Y.-R. Zheng and P. J. Stang, Chem. Rev., 2013, 113, 734-777.

5 P. Mal, B. Breiner, K. Rissanen and J. R. Nitschke, Science, 2009, 324, 1697-1699.

6 O. Shyshov, R.-C. Brachvogel, T. Bachmann, R. Srikantharajah, D. Segets, F. Hampel, R. Puchta and M. von Delius, Angew. Chem., Int. Ed., 2017, 56, 776-781.
7 R. Sekiya, M. Fukuda and R. Kuroda, Org. Biomol. Chem., 2017, 15, 4328-4335.

8 D. Preston, J. E. M. Lewis and J. D. Crowley, J. Am. Chem. Soc., 2017, 139, 2379-2386.

9 L. Yang, X. Jing, B. An, C. He, Y. Yang and C. Duan, Chem. Sci., 2018, 9, 1050-1057.

10 Y. Fang, J. A. Powell, E. Li, Q. Wang, Z. Perry, A. Kirchon, X. Yang, Z. Xiao, C. Zhu, L. Zhang, F. Huang and H.-C. Zhou, Chem. Soc. Rev., 2019, 48, 4707-4730.

11 M. Yoshizawa, J. K. Klosterman and M. Fujita, Angew. Chem., Int. Ed., 2009, 48, 3418-3438.

12 D. M. Vriezema, M. Comellas Aragonès, J. A. A. W. Elemans, J. J. L. M. Cornelissen, A. E. Rowan and R. J. M. Nolte, Chem. Rev., 2005, 105, 1445-1489.

13 C. Tan, D. Chu, X. Tang, Y. Liu, W. Xuan and Y. Cui, Chem. - Eur. J., 2019, 25, 662-672.

14 M. Yoshizawa, M. Tamura and M. Fujita, Science, 2006, 312, 251-254.

15 T. A. Bender, M. Morimoto, R. G. Bergman, K. N. Raymond and F. D. Toste, J. Am. Chem. Soc., 2019, 141, 1701-1706.

16 S. M. Bierschenk, R. G. Bergman, K. N. Raymond and F. D. Toste, J. Am. Chem. Soc., 2020, 142, 733-737.

17 C. M. Hong, R. G. Bergman, K. N. Raymond and F. D. Toste, Acc. Chem. Res., 2018, 51, 2447-2455.

18 W. Cullen, M. Misuraca, C. Hunter, N. Williams and M. Ward, Nat. Chem., 2016, 8, 231-236.

19 V. Martí-Centelles, A. Lawrence and P. Lusby, J. Am. Chem. Soc., 2018, 140, 2862-2868.

20 S. Saha, I. Regeni and G. H. Clever, Coord. Chem. Rev., 2018, 374, 1-14.

21 S. J. Dalgarno, N. P. Power and J. L. Atwood, Coord. Chem. Rev., 2008, 252, 825-841.

22 A. J. McConnell, C. S. Wood, P. P. Neelakandan and J. R. Nitschke, Chem. Rev., 2015, 115, 7729-7793.

23 L.-J. Chen and H.-B. Yang, Acc. Chem. Res., 2018, 51, 26992710.

24 S. Ganta and D. K. Chand, Inorg. Chem., 2018, 57, 51455158.

25 R. Lavendomme, T. K. Ronson and J. R. Nitschke, J. Am. Chem. Soc., 2019, 141, 12147-12158.

26 S. Chakraborty, K. J. Endres, R. Bera, L. Wojtas, C. N. Moorefield, M. J. Saunders, N. Das, C. Wesdemiotis and G. R. Newkome, Dalton Trans., 2018, 47, 14189-14194.

27 R. Sekiya, M. Fukuda and R. Kuroda, J. Am. Chem. Soc., 2012, 134, 10987-10997.

28 M. Han, Y. Luo, B. Damaschke, L. Gómez, X. Ribas, A. Jose, P. Peretzki, M. Seibt and G. H. Clever, Angew. Chem., Int. Ed., 2016, 55, 445-449.

29 R.-J. Li, J. J. Holstein, W. G. Hiller, J. Andréasson and G. H. Clever, J. Am. Chem. Soc., 2019, 141, 2097-2103.

30 A. J. Musser, P. Neelakandan, J. M. Richter, H. Mori, R. H. Friend and J. R. Nitschke, J. Am. Chem. Soc., 2017, 139, 12050-12059.

31 Y. Furutani, H. Kandori, M. Kawano, K. Nakabayashi, M. Yoshizawa and M. Fujita, J. Am. Chem. Soc., 2009, 131, 4764-4768. 
32 W. Cullen, H. Takezawa and M. Fujita, Angew. Chem., Int. Ed., 2019, 58, 9171-9173.

33 S. Freye, J. Hey, A. Torras-Galán, D. Stalke, R. Herbst-Irmer, M. John and G. H. Clever, Angew. Chem., Int. Ed., 2012, 51, 2191-2194.

34 M. Frank, M. D. Johnstone and G. H. Clever, Chem. - Eur. J., 2016, 22, 14104-14125.

35 M. Frank, J. Ahrens, I. Bejenke, M. Krick, D. Schwarzer and G. H. Clever, J. Am. Chem. Soc., 2016, 138, 8279-8287.

36 M. Frank, J. Hey, I. Balcioglu, Y.-S. Chen, D. Stalke, T. Suenobu, S. Fukuzumi, H. Frauendorf and G. H. Clever, Angew. Chem., Int. Ed., 2013, 52, 10102-10106.

37 R. Zhu, J. Lübben, B. Dittrich and G. H. Clever, Angew. Chem., Int. Ed., 2015, 54, 2796-2800.

38 J. M. Dieterich, G. H. Clever and R. A. Mata, Phys. Chem. Chem. Phys., 2012, 14, 12746-12749.

39 S. Löffler, J. Lübben, L. Krause, D. Stalke, B. Dittrich and G. H. Clever, J. Am. Chem. Soc., 2015, 137, 1060-1063.

40 S. Löffler, A. Wuttke, B. Zhang, J. J. Holstein, R. A. Mata and G. H. Clever, Chem. Commun., 2017, 53, 11933-11936.

41 J. Clayden, N. Greeves and S. G. Warren, Organic chemistry, Oxford University Press, Oxford, New YorK, 2nd edn, 2012 .
42 T. Murase, Y. Nishijima and M. Fujita, J. Am. Chem. Soc., 2012, 134, 162-164.

43 R. Ziegert and S. Bräse, Synlett, 2006, 2119-2123.

44 O. Dechy-Cabaret, F. Benoit-Vical, C. Loup, A. Robert, H. Gornitzka, A. Bonhoure, H. Vial, J.-F. Magnaval, J.-P. Séguéla and B. Meunier, Chem. - Eur. J., 2004, 10, 1625-1636.

45 R. C. Murphy and K. M. Johnson, J. Biol. Chem., 2008, 283, 15521-15525.

46 N. Hoffmann, Chem. Rev., 2008, 108, 1052-1103.

47 M. DeRosa, Coord. Chem. Rev., 2002, 233-234, 351-371.

48 J. Eberhard, K. Peuntinger, S. Rath, B. Neumann, H.-G. Stammler, D. M. Guldi and J. A. Mattay, Photochem. Photobiol. Sci., 2014, 13, 380-396.

49 C. C. Le, M. K. Wismer, Z.-C. Shi, R. Zhang, D. V. Conway, G. Li, P. Vachal, I. W. Davies and D. W. C. MacMillan, ACS Cent. Sci., 2017, 3, 647-653.

50 K. Feng, R.-Y. Zhang, L.-Z. Wu, B. Tu, M.-L. Peng, L.-P. Zhang, D. Zhao and C.-H. Tung, J. Am. Chem. Soc., 2006, 128, 14685-14690.

51 W. M. Bloch, Y. Abe, J. J. Holstein, C. M. Wandtke, B. Dittrich and G. H. Clever, J. Am. Chem. Soc., 2016, 138, 13750-13755. 